\title{
Thermal requirements for development and resource partitioning in aphidophagous guilds
}

\author{
ANTHONy F.G. DIXON ${ }^{1}$, VoJTĚch JAROŠÍK ${ }^{2,4}$ and Alois HONĚK ${ }^{3}$ \\ ${ }^{1}$ School of Biological Sciences, University of East Anglia, Norwich, NR4 7TJ, UK; e-mail: a.f.dixon@uea.ac.uk \\ ${ }^{2}$ Department of Ecology, Charles University, CZ-128 43 Prague 2, Czech Republic; e-mail: jarosik@cesnet.cz \\ ${ }^{3}$ Research Institute of Crop Production, CZ-161 06 Prague 6, Ruzyně, Czech Republic; e-mail: honek@vurv.cz \\ ${ }^{4}$ Institute of Botany, Academy of Sciences of the Czech Republic, CZ-252 43 Průhonice, Czech Republic; e-mail: jarosik@cesnet.cz
}

Key words. Coccinellidae, Syrphidae, aphidophagous guilds, coexistence, intraguild predation, lower developmental threshold, phylogenetic constraint, cereals, sycamore

\begin{abstract}
The duration of the increase, peak and decline in abundance of the immature stages of sycamore and cereal aphids each year is ephemeral. These temporary resources are exploited by a sequence of aphidophagous insect predators. The temporal sequence in the appearance of the immature stages of coccinellids and syrphids in the sycamore and cereal aphid systems is defined. In spring in the sycamore aphid system and early summer in the cereal aphid system the immature stages of syrphids consistently appeared before those of coccinellids. In the case of the sycamore aphid the autumnal peak in abundance was on average larger than the spring peak, and although attacked by more syrphids, it was not exploited by coccinellids. These temporal patterns in the attack sequence are associated with a difference in the lower developmental thresholds (LDT) of these two groups of predators. The LDT of syrphids $\left(4^{\circ} \mathrm{C}\right)$ enables them to be active at lower temperatures and to develop faster between $10^{\circ}$ and $27^{\circ} \mathrm{C}$ than coccinellids, whose LDT is $10^{\circ} \mathrm{C}$. As a consequence, early in the year, when temperatures are low but increasing, syrphids appear before and complete their development more quickly than coccinellids, and in the latter half of the year, when temperatures are generally lower and decreasing, only syrphids are likely to be able to complete their development before the aphids disappear. Thus, the niche shift between syrphids and coccinellids is possibly more a consequence of a phylogenetic constraint than a response to competition and or intraguild predation. The relevance of these findings for the ecology of intraguild predation is discussed.
\end{abstract}

\section{INTRODUCTION}

Resource utilization is usually viewed in terms of food species size (Schoener, 1974) with each species in a predator guild adapted to exploit a particular sized species of prey. Large species of predator exploit large species of prey and vice versa. That is, species in a guild are able to displace other species from a particular portion of the resource space by virtue of their being better adapted to exploit that particular species of prey in that resource space.

Increasing size in predatory coccinellids is also associated with increase in size and/or mobility of their prey. The smallest species of predatory coccinellids feed on mites, and the largest on caterpillars and beetle larvae (Dixon \& Hemptinne, 2001). On a finer scale, however, there appears to be no association between the size of an aphidophagous predator and that of the species of aphid it exploits.

Aphid colonies in temperate regions generally increase, peak and decline in abundance, and are exploited by a sequence of predators, which is consistent from year to year (Hodek \& Honěk, 1996; Dixon, 2000). Intraguild predation is defined as the killing and eating of species that use similar resources and are thus potential competitors. It is distinguished from competition because one participant (the predator) accrues an immediate energetic gain, and differs from classical predation because the act reduces potential competition (Polis \& Holt, 1992). It is also assumed that the predators are able to coexist because the top predators have a greater affect on the abundance of intermediate predators than on the prey. Intraguild predation is currently seen as a major factor structuring predatory guilds. However, the vast literature on intraguild predation involving aphidophagous predators assumes there are no costs involved in capturing and eating intraguild prey, and does not discuss the relevance of the results to the ecology and evolution of intraguild predation.

Here two aphidophagous predatory guilds are studied with the aim of determining whether the temporal attack sequences of syrphids and coccinellids differ. Then a process that might account for the observed difference is presented. Finally the consequences of the findings for intraguild predation are discussed.

\section{MATERIAL AND METHODS}

\section{Temporal attack sequences}

The numbers of sycamore aphids (Drepanosiphum platanoides Schrank) and their natural enemies were monitored on four sycamore trees (Acer pseudoplatanus L.) from 1963-1973. This was done by counting weekly the numbers present on 80 leaves selected at random from the lower canopy of each of the trees (Dixon, 2005). That is, 4 trees were sampled for 11 years and the resultant data set consisted of 44 tree years. The first records in spring of the early stages of the coccinellid Adalia bipunctata L. and the syrphids Episyrphus balteatus (DeGeer) and Syrphus vitripennis Meigen were of particular interest for 
this study. In autumn it was the number of syrphids. The trees were located in deciduous woodland on the Rossdhu estate, on the west shore of Loch Lomond, $34 \mathrm{~km}$ north west of Glasgow, U.K $\left(56^{\circ} 10^{\prime} \mathrm{N}, 4^{\circ} 40^{\prime} \mathrm{W}\right)$.

Abundance of coccinellid and syrphid larvae was monitored in winter wheat at Praha - Ruzyně $\left(50^{\circ} 06^{\prime} \mathrm{N} 14^{\circ} 15^{\prime} \mathrm{E}\right)$ between June 29 and July 23, 2004, in a densely planted (c. 0.1 ha with a leaf area index LAI at the time of sampling $>2.5$ ) and sparsely planted crop (c. 1 ha marginal section of a 9 ha stand, LAI < 1.3). Both crops were sampled at $2-3$ day intervals, in both the morning (06:00-07:30 h) and at sunset (20:00-21:00), by taking 15 samples, each consisting of 10 sweeps with an entomological net (30 $\mathrm{cm}$ diameter) along a standard transect. For each sample the average number per 10 sweeps of syrphid (3rd instar) and coccinellid (3rd and 4th instar) larvae were calculated. The syrphid larvae were mainly E. balteatus and Scaeva pyrastri (L.), plus a few Sphaerophoria spp., Melanostoma spp. and Platycheirus spp. (identified later by the presence of juvenile adults in swept material). The coccinellid larvae were mainly Coccinella septempunctata L., plus a few of Propylea quatuordecimpunctata (L.). The abundance of coccinellid and syrphid larvae in the two crops was different but the time of their appearance was similar. The cumulative number $( \pm \mathrm{SE})$ of coccinellid and syrphid larvae caught in the two crops over the sampling period were calculated and plotted against time. The difference in the time of occurrence of syrphid and coccinellid larvae was tested using analysis of covariance, with cumulative proportions of larvae as the response variable, kind of larva (syrphid vs. coccinellid) as the factor and sampling date as the covariate. For this analysis only the linear section of cumulative curves, between July 2-17, were used. The time when the cumulative catch was half of the cumulative total was used to determine the period (days) that elapsed between first syrphid and coccinellid occurrence.

Aphid numbers were determined in three experimentally thinned plots, in a section of a 9 ha crop by the dense stand, using the standard procedure for recording aphid abundance (e.g. Honěk \& Martinková, 1999). The aphids were counted on the leaves and ears of 50-300 tillers at weekly intervals, from immigration until they disappeared from mature plants. The average aphid numbers tiller ${ }^{-1}$ on each date was calculated. As sampling for aphids is time consuming it was not repeated in the stands where predator larvae were sampled.

\section{Process determining the temporal sequences}

The rates of development, $R D$ (i.e. proportion of total preimaginal development occurring per unit time), and lower developmental thresholds, $L D T$ (i.e. the temperature, $t$, when development ceases), were compared between syrphid and coccinellid species. The data used in this comparison are made up of 34 populations of 22 species of aphid eating coccinellids, listed in Jarošík et al. (2003), and four populations of four different species of aphid eating syrphids. The data for syrphids are those published by Ankersmit et al. (1986) for E. balteatus, by Benestad (1970) for Metasyrphus corollae (F.), cited in Jarošík et al. (2002), and by Soleyman-Nezhadiyan \& Laughlin (1998) for Melangyna viridiceps Macquart and Symosyrphus grandicornis Macquart. The data for each species or population is for three or more constant temperatures, falling within the range of the linear relationship between developmental rate and temperature.

To compare the lower developmental threshold (LDT) of coccinellids and syrphids, the relationship between the rate of development $(R D)$ and temperature $(t)$ was described, separately for coccinellids and syrphids, by a linear regression: $R D=a+$ $b$.t, where $a$ is the intercept with the $y$-axis, and $b$ the slope of

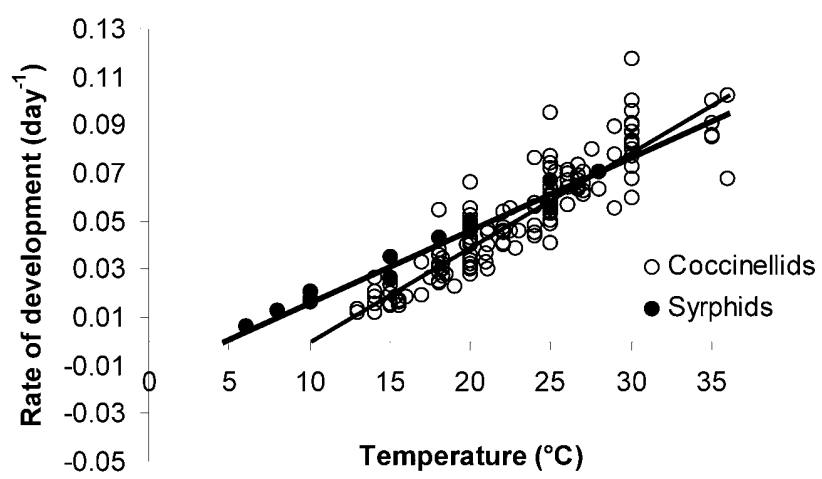

Fig. 1. Relationship between the rate of development $(R D)$ and temperature $(t)$ of aphid eating coccinellids and syrphids, fitted by ANCOVA with a different intercept and slope for coccinellids and syrphids $\left(\mathrm{F}=262.4 ; \mathrm{df}=3,152 ; \mathrm{P}<<0.001 ; \mathrm{R}^{2}=\right.$ 83.8\%). Coccinellids: $R D=-0.039+0.0039 t(\mathrm{~F}=640.0 ; \mathrm{df}=$ 1,$\left.139 ; \mathrm{P}<<0.001 ; \mathrm{R}^{2}=82.2 \%\right)$; syrphids: $R D=-0.011+$ $0.0029 t\left(\mathrm{~F}=424.9 ; \mathrm{df}=1,13 ; \mathrm{P}<<0.001 ; \mathrm{R}^{2}=97.0 \%\right)$.

the linear function. From this equation, the lower developmental threshold, i.e. the temperature when $R D=0$ and $t=L D T$, was estimated as $L D T=-a / b$ (e.g. Jarošík et al. 2002). The $95 \%$ confidence intervals of the $L D T s$ of coccinellids and syrphids were used to determine whether the $L D T$ s differed significantly. This was done by shifting the $y$-axis to their LDTs (at which points their developmental rates intercept the temperature axis, Fig. 1) by subtracting $L D T$ s from temperature values and by calculating standard errors of the shifted zero intercepts (see e.g. Crawley 1993, p. 276-277).

To compare the rates of development of coccinellids and syrphids, the data were evaluated by ANCOVA in which the rate of development was regressed on temperature with a different intercept and a different slope for coccinellids and syrphids. Parameters of this model were inspected for significance by deletion tests, following Crawley (1993). That a single value for the rate of development and LDT can be used for all species of coccinellids and syrphids was verified by calculating the value of the rate of development separately for each species, and then comparing the $95 \%$ confidence intervals of the average values for coccinellids and syrphids.

Whether LDTs are heterogeneous among coccinellids and syrphids was further verified by metaanalysis, a statistical synthesis of the results of separate, independent experiments. The studies on syrphids and coccinellids were grouped taxonomically, and the outcome of each analysis on LDT represented by a quantitative index, of the effect size, which is independent of sample size and the scale of measurement of the population of the species. The null hypothesis that there are no differences in LDT between syrphids and coccinellids was tested following Gurevitch \& Hedges (2001) and Jarošík et al. (2004).

\section{RESULTS}

\section{Temporal attack sequences}

The reproductive rate of the sycamore aphid changes markedly during the season. It is high when the leaves are actively growing and senescing, and at a low rate, or ceases altogether, when the leaves are mature. This results in two peaks in abundance of immature aphids: one in late spring early summer and the other in autumn (Dixon, 1970). The immature stages of the insect predators are 


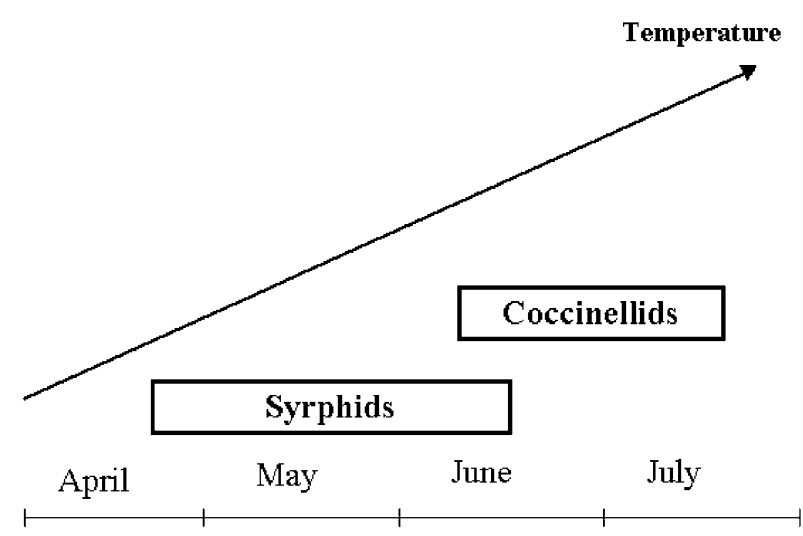

Fig. 2. The range in the time of first occurrence on sycamore in spring and early summer in Scotland, UK, of the immature stages of coccinellids and syrphids.

mainly associated with these peaks in abundance (Dixon, 2005).

In spring, on the nine occasions ( 9 tree-years) when the immature stages of both syrphids and coccinellids were found, those of the syrphids were recorded on average 35 days earlier than those of the coccinellids and on none of these occasions did ladybirds appear before syrphids (Fig. 2). In autumn the peak populations of young aphids were on average larger than in spring (Dixon, 2005). Associated with this greater abundance of aphids there were on average four times more syrphids in autumn than in spring. In marked contrast to spring no immature stages of coccinellids were recorded in autumn.

In winter wheat stands aphids peaked in abundance around the middle of the year (Fig. 3). The oviposition and development of the early larval stages of the predators coincided with the peak in abundance of aphids. Third and fourth instar larvae recorded in this study appeared later, when the aphids were already declining in abundance. In 2004 the time to collecting 50\% of syrphid larvae (July 5) preceded that of collecting $50 \%$ of coccinellid larvae (July 16) by 11 days (Fig. 4). The time of occurrence of these events for both groups of predators is significantly different (ANCOVA: $\mathrm{F}=72.4 ; \mathrm{df}=1,13 ; \mathrm{P}$ $<0.001)$.

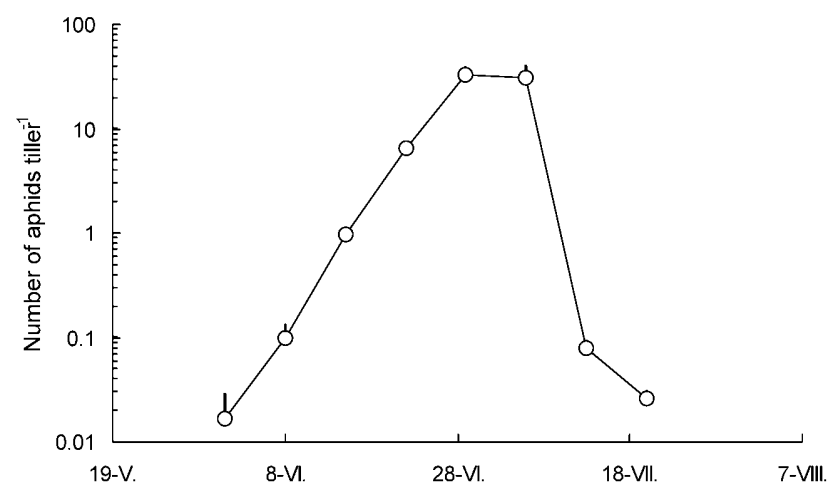

Fig. 3. The trend in time in the abundance of the aphids on the leaves and ears of wheat growing in a sparse stand in 2004 in Prague, Czech Republic. The points represent mean $(+\mathrm{SE})$ number of aphids tiller ${ }^{-1}$.

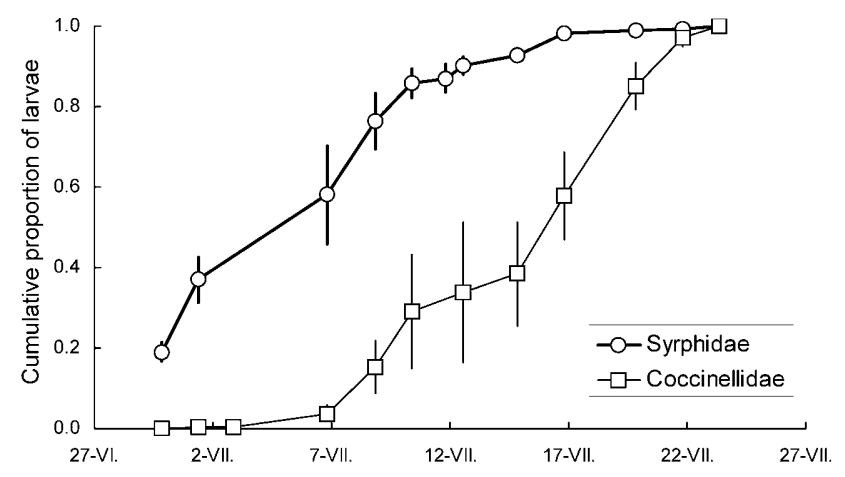

Fig. 4. The increase in cumulative numbers (SE) of coccinellid and syrphid larvae, from 27 June to 27 July, in samples collected from a crop of winter wheat in 2004 in Prague, Czech Republic. The number are expressed as the proportion of the total catch over the sampling period $(=1)$.

\section{Process determining the temporal sequences}

Lower developmental threshold $(L D T)$ of the coccinellids (mean $\pm 95 \%$ confidence interval) is much higher $\left(9.952 \pm 0.0043^{\circ} \mathrm{C}\right)$ than that of the syrphids $(3.927 \pm$ $0.0043^{\circ} \mathrm{C}$ ). Consequently, at temperatures above the average $L D T$ for syrphids and below that for coccinellids, only syrphids can develop (Fig. 1). In addition, the rates of development differ both in slope (deletion test in ANCOVA: $\mathrm{F}=6.38 ; \mathrm{df}=1,153 ; \mathrm{P}<0.05)$ and intercept (deletion test in ANCOVA: $\mathrm{F}=13.60 ; \mathrm{df}=1,153 ; \mathrm{P}<$ 0.001 ). Therefore, at temperatures above $10^{\circ}$ and below $27^{\circ} \mathrm{C}$ syrphids on average develop faster than coccinellids. Above $27^{\circ} \mathrm{C}$ coccinellids develop faster than syrphids (Fig. 1). This is supported by the fact that the $95 \%$ confidence intervals of the rates of development of all coccinellid species overlap, which indicates that all coccinellids are likely to have the same rate of development. The same is true for syrphids (Fig. 5). In addition, a metaanalysis indicated that LDTs of coccinellids and syrphids are significantly different $\left(\chi^{2}=28059.95 ; \mathrm{df}=1 ; \mathrm{P}\right.$ $<<0.00001)$.

Thus, in spring / early summer in these systems the occurrence of syrphids before coccinellids is possibly determined by the syrphids having a lower LDT and higher rates of development at temperatures up to $27^{\circ} \mathrm{C}$. At this time of the year temperature and rates of development are generally increasing. In autumn the absence of coccinellids is possibly because the temperature then is generally lower and decreasing. Thus development of coccinellids in autumn is likely to be prolonged, which would considerably reduce their chances of reaching maturity. As a consequence adult coccinellids, although present, do not continue ovipositing into autumn as syrphids do, possibly because there are insufficient day degrees left for them to complete their development before the end of the season. Instead, in autumn adult coccinellids are more likely to be foraging for resources to build up their fat bodies prior to entering diapause for the winter than for reproducing. 


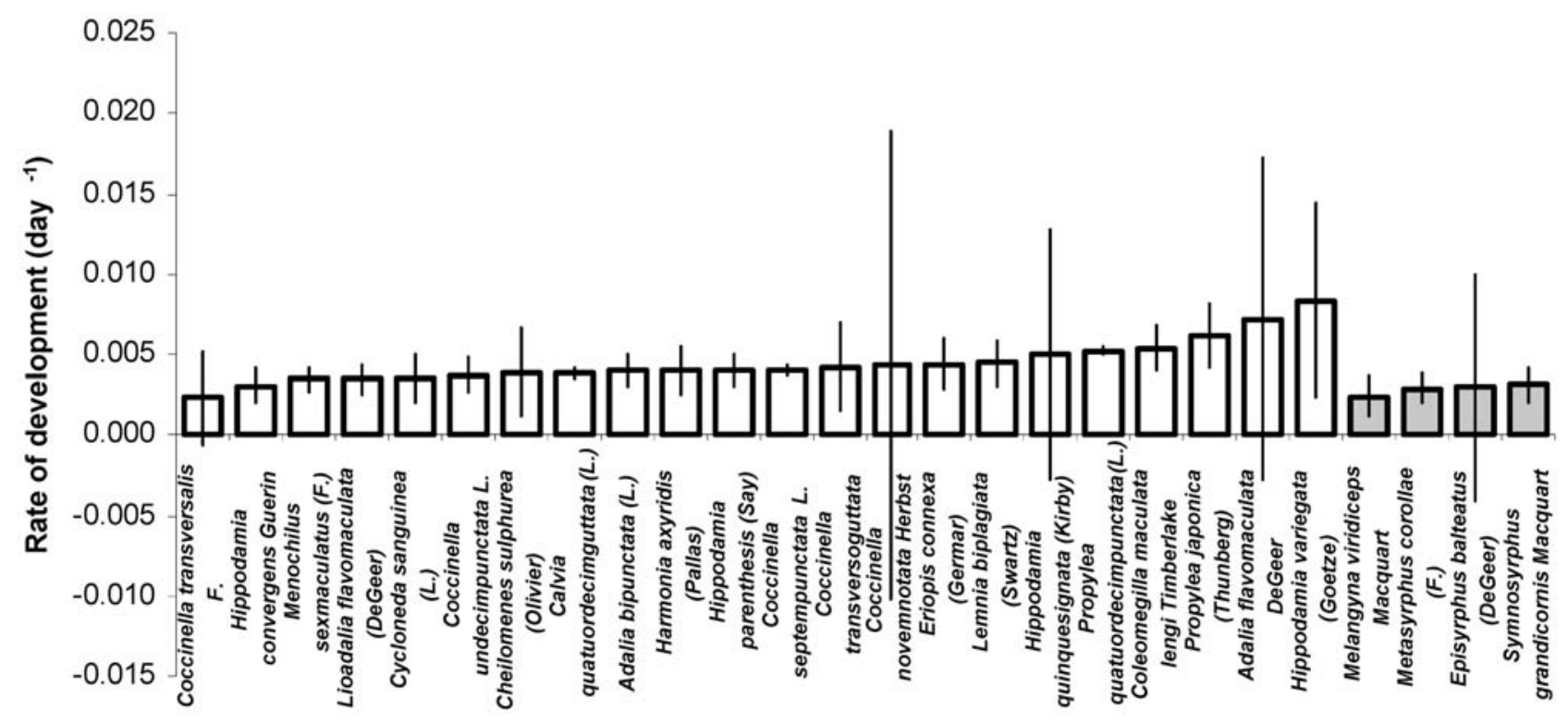

Fig. 5. Rates of development of individual coccinellid (white) and syrphid (grey) species with their 95\% confidence intervals (CI). The negative values of CI indicate statistically insignificant rates of development.

\section{DISCUSSION}

This study has revealed that for coccinellids and syrphids there is evidence of temporal structuring in aphidophagous guilds. It is tempting to think that this temporal shift could be in response to competition and/or intraguild predation. Certainly, the larvae of coccinellids and syrphids eat one another (Agarwala \& Yasuda, 2001; Hindayana et al., 2001). However, the process underlying this niche shift appears to be a difference in the lower developmental thresholds of these two groups of aphid predators. A plot of the relationship between developmental rate $(1 / \mathrm{D})$ and temperature for 48 species of predatory coccinellids, from different parts of the world, indicates they all have the same lower developmental threshold (Dixon et al., 1997). In the case of syrphids the data set presented here, although much smaller, comes from different parts of the world with very different climates and shows a similar trend that indicates that they all apparently have very similar lower developmental thresholds. This might indicate that the "shift" is more a consequence of a phylogenetic constraint than a response to competition and/or intraguild predation. If this is the case then it raises the possibility that the difference in lower developmental threshold might have facilitated the coexistence of these two groups of predators. The difference in lower developmental threshold established between syrphids and coccinellids is that typical for "cold" and "warm" adapted poikilotherms (Trudgill, 1995). This difference could result in a "shift" in the time of occurrence of these two groups of predators, which is most marked in cool conditions.

Coexistence of two or more predators exploiting the same resource is possible if the predatory guild consists of top as well as intermediate predators, and the top predators have a greater affect on the abundance of the intermediate predators than on that of the aphid (Polis \& Holt, 1992). However, in neither of the systems studied is there a top predator. There is an increasing body of experimental evidence that indicates that Harmonia axyridis (Pallas) is a top predator (Dixon, 2000; Sato et al., in prep.). However, the presence of top predators in aphidophagous guilds is rare. If this is the case then the problem of how two or more predators can coexist remains to be resolved. It is possible that the abundance of the predators is regulated by their natural enemies or by cannibalism. The latter is widely reported in coccinellids (Hodek \& Honěk, 1996; Dixon, 2000) and syrphids (e.g., Clark, 1963 and many other references). In the case of coccinellids there is strong empirical evidence that cannibalism acts as a strong density dependent regulating factor (Mills, 1982; Osawa, 1993). If species of coccinellids and syrphids, through cannibalism, have a greater effect on their own abundance than on that of the other predators in the guild then they should coexist. This is still an open question but at least there is some supporting evidence for this suggestion.

Intraguild predation is ubiquitous in aphidophagous guilds. The publication of Polis \& Holt's (1992) seminal paper on intraguild predation provoked a plethora of publications on this topic. However, this has done little to forward our understanding of the ecology of intraguild predation. This is most likely to come from a closer attention to the patterns and processes determining or associated with predatory guilds and the experimental testing of the assumptions of intraguild predation theory.

ACKNOWLEDGEMENTS. We are indebted to F. Gilbert for confirming that cannibalism is widely reported for syrphids and bringing 23 references on the subject to our attention. A.H. was supported by grant no. QD1350 and VZ3 of the Ministry of Agriculture of the Czech Republic and V.J. by grant MSM 0021620828 . 


\section{REFERENCES}

Agarwala B.K. \& Yasuda H. 2001: Larval interactions in aphidophagous predators: effectiveness of wax cover as defence shield of Scymnus larvae against predation by syrphids. Entomol. Exp. Appl. 100: 101-107.

Ankersmit G.W., Dijkman H., Keuning N.J., Sins A. \& Tacoma H.M. 1986: Episyrphus balteatus as a predator of the aphid Sitobion avenae on winter wheat. Entomol. Exp. Appl. 42: 271-277.

Benestad E. 1970: Laboratory experiments on the biology of Syrphus corollae (Fabr.) (Dipt., Syrphidae). Norsk Entomol. Tidsskr. 17: 77-85.

CLARK L.R. 1963: The influence of predation by Syrphus sp. on the numbers of Cardiaspina albitextura (Psyllidae). Austr. J. Zool. 11: 470-487.

CRAwley M.J. 1993: GLIM for Ecologists. Blackwell Science, Oxford, 379 pp.

Dixon A.F.G. 1970: Quality and availability of food for a sycamore aphid population. In Watson A. (ed.): Animal Populations in Relation to their Food Resources. Blackwell, Oxford, pp. $277-287$.

Dixon A.F.G. 2000: Insect Predator-Prey Dynamics: Ladybird Beetles and Biological Control. Cambridge University Press, Cambridge, 257 pp.

Dixon A.F.G. 2005: Insect Herbivore-Host Dynamics: Tree Dwelling Aphids. Cambridge University Press, Cambridge, 199 pp.

Dixon A.F.G. \& Hemptinne J.-L. 2001: Body size distribution in predatory ladybird beetles reflects that of their prey. Ecology 82: $1847-1856$.

Dixon A.F.G., Hemptinne J.-L. \& Kindlmann P. 1997: Effectiveness of ladybirds as biological control agents: patterns and processes. Entomophaga 42: 71-83.

Gurevitch J. \& Hedges L.V. 2001: Combining the results of independent experiments. In Scheiner S.M. \& Gurevitch J. (eds): Design and Analysis of Ecological Experiments. Oxford University Press, New York, pp. 347-369.

Hindayana D., Meyhofer R., Schulz D. \& Poehling H.-M. 2001: Intraguild predation among hoverfly Episyrphus bal- teatus de Geer (Diptera: Syrphidae) and other aphidophagous predators. Biol. Contr. 20: 236-246.

Hodek I. \& HonĚK A. 1996: Ecology of Coccinellidae. Kluwer Academic Publishers, Dordrecht, 464 pp.

HonĚK A. \& MARTINKOVÁ Z. 1999: Host-plant mediated influences on population development of Sitobion avenae (Sternorrhyncha: Aphididae). Eur. J. Entomol. 96: 135-141.

JARošíK V., HonĚK A. \& DiXon A.F.G. 2002: Developmental rate isomorphy in insects and mites. Am. Nat. 160: 497-510.

Jarošík V., Polechová J., Dixon A.F.G. \& HonĚK A. 2003: Developmental isomorphy in ladybirds (Coleoptera: Coccinellidae). In Soares A.O., Ventura M.A., Garcia V., Hemptinne J.-L. (eds): Proceedings of the 8th International Symposium on Ecology of Aphidophaga: Biology, Ecology and Behaviour of Aphidophagous Insects. Arquipélago. Life and Marine Sciences. Supplement 5, pp. 55-64

Jarošík V., Kratochvíl L., HonĚK A., Dixon A.F.G. 2004: A general rule for the dependence of developmental rate on temperature in ectotherms. Proc. R. Soc. Lond. (B) (Suppl.) 271: S219-S221.

Mills N.J. 1982: Voracity, cannibalism and coccinellid predation. Ann. Appl. Biol. 101: 144-148.

Osawa N. 1993: Population field studies of the aphidophagous ladybird beetle Harmonia axyridis (Coleoptera: Coccinellidae): life tables and key factor analysis. Res. Popul. Ecol. 35: 335-348.

Polis G.A. \& Holt R.D. 1992: Intraguild predation: The dynamics of complex trophic interactions. Trends Ecol. Evol. 7: 151-154.

SCHOENER T.W. 1974: Resource partitioning in ecological communities. Science 185: 27-39.

Soleyman-Nezhadiyan E. \& Laughlin R. 1998: Voracity of larvae, rate of development in eggs, larvae and pupae, and flight seasons of adults of the hoverflies Melangyna viridiceps Macquart and Symosyrphus grandicornis Macquart (Diptera: Syrphidae). Austr. J. Entomol. 37: 243-248.

TRUDGILL D.L. 1995: Why do tropical poikilothermic organisms tend to have higher threshold temperatures for development than temperate ones? Funct. Ecol. 9: 136-137.

Received December 13, 2004; revised and accepted May 2, 2005 